البصيرة: مجلة الدراسات الإسلامية

AL-BASHIRAH: JOURNAL OF ISLAMIC STUDIES

Vol. 2 No. 2 (2020): 221-237

ISSN: $2807-2170$

Website: https://journal.stiba.ac.id

\title{
حوكمة الزكاة في ضوء مقاصد الشريعة
}

\author{
رحت الله حيدري \\ كلية الشريعة، جامعة غزني - أفغانستان
}

rahmatullah.wa@gmail.com البريد الإلكتروين

$$
\begin{aligned}
& \text { أرسلاح ظفري } \\
& \text { جامعة نجم الدين أربكان - تركيا طان } \\
& \text { arsalahzafari99@gmail.com : البريد الإلكتروني الدركان }
\end{aligned}
$$

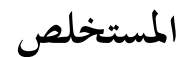

قد تناول الباحثان من خلال هذه الدراسة حوكمة الزكاة في ضوء مقاصد الشريعة، حيث أن حوكمة الزكاة لها مقاصد

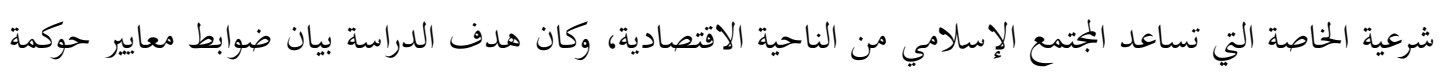

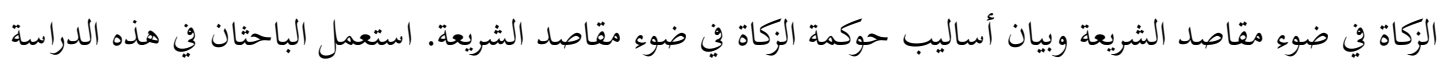

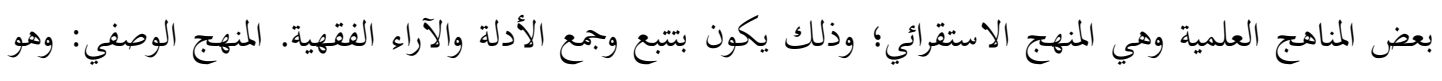

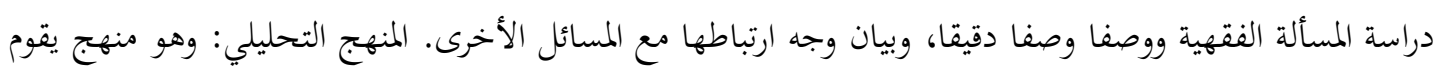

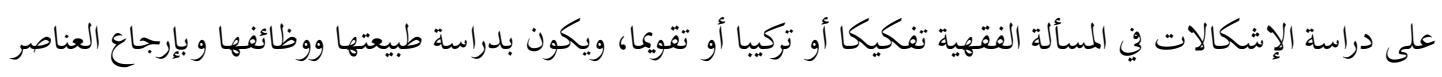
إلى أصولها. ونتيجة البحث تدل على أن أساليب الحوكمة لتحقيق مقاصد الشريعة هي انضباط أعضاء الجهاز الإداري

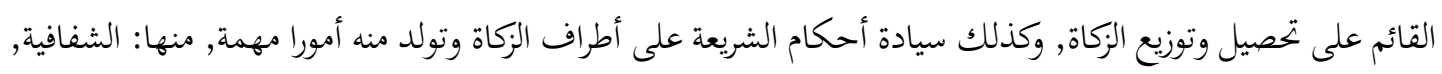

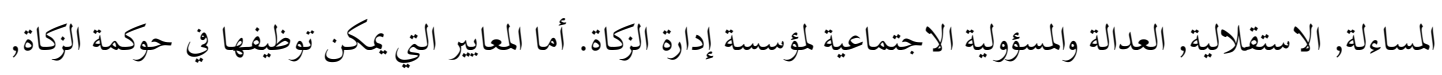

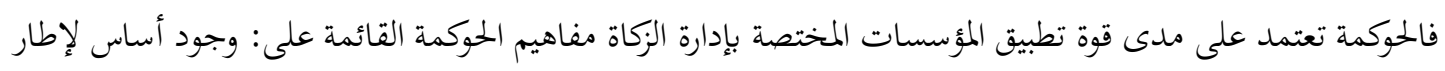

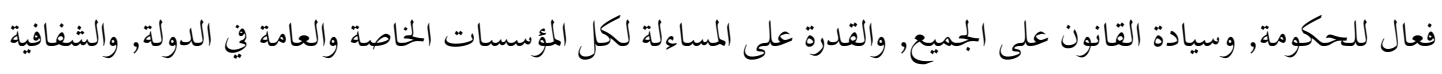

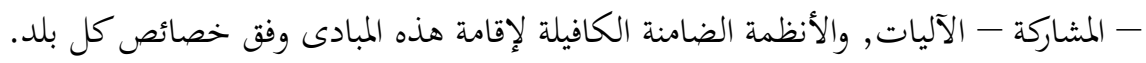

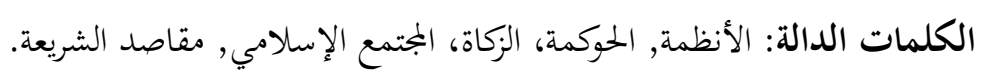




هبلة
AL-BASHIRAH: JOURNAL OF ISLAMIC STUDIES
Vol. 2 No. 2 (2020): 221-237
ISSN: $2807-2170$
Website: https://journal.stiba.ac.id

ZAKAT GOVERNANCE IN THE CONTEXT OF MAQĀSTID SYARIAH

\author{
Rahmatullah Hidri \\ Ghazni University, Afghanistan \\ Email: rahmatullah.wa@gmail.com \\ Arsalah Zafari \\ Necmettin Erbakan University, Turkey \\ Email: arsalahzafari99@gmail.com
}

\begin{abstract}
This research discusses zakat governance in the context of sharia maqāsid, because zakat governance has a special legitimacy purpose that helps Islamic communities in economic problems. The purpose of this study is to clarify the standards of governance control of zakat sharia maqāsid perspective and to demonstrate the method of zakat governance according to maqāșid sharia. In this study, researchers used several scientific methods, including: (1) inductive methods to track and collect fiqhiyyah arguments and arguments; (2) descriptive approach, which is the study of the problem of jurisprudence with an accurate description, as well as an explanation of its correlation with various other problems; (3) Analytical methods are methods based on the study of jurisprudic problems in digging, synthesizing and evaluating, and studying their properties and functions in returning elements to their origin. The results showed that the method of zakat governance to achieve sharia maqāsid is the discipline of members of administrative bodies in collecting and distributing zakat, as well as the supremacy of sharia on the provisions of the berzakat parties, and born from it several important things, among others: transparency, accountability, independence, justice, and social responsibility of zakat management institutions. The criteria that can be used in zakat governance, where governance depends on the extent to which special institutions implement the concepts of governance, namely: the existence of an effective framework basis for the government, the rule of law for all, the capacity of accountability for all private and public institutions in the country (transparency, participation and mechanisms) and the guarantee system of upholding these principles in accordance with the characteristics of each country.
\end{abstract}

Keywords: regulation, governance, zakat, Islamic society, maqāșid sharia. 
إن أحكام الشريعة جمعاء جاءت بقانون الحكمة والمصلحة، وإن تفعيل الفقه المقاصدي مرتبط

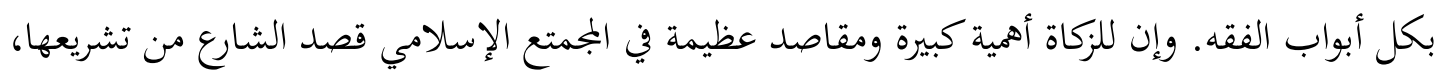

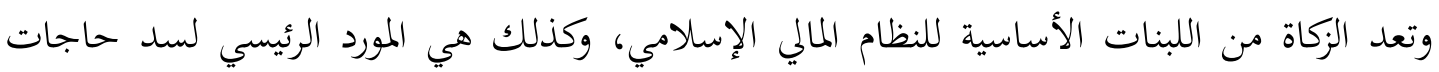

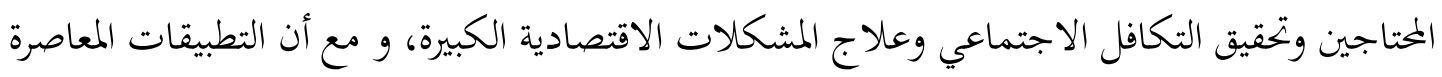

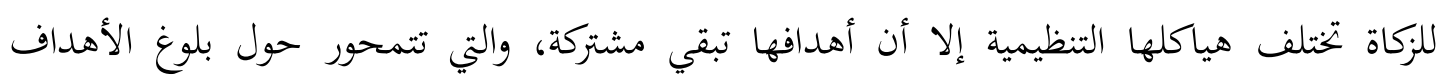



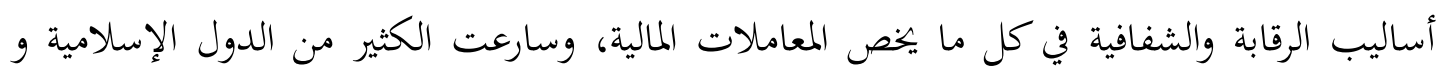

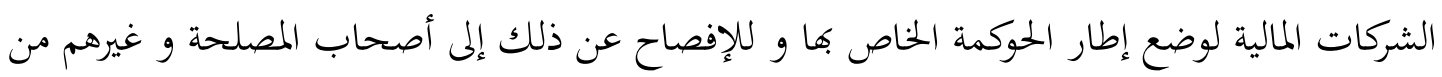

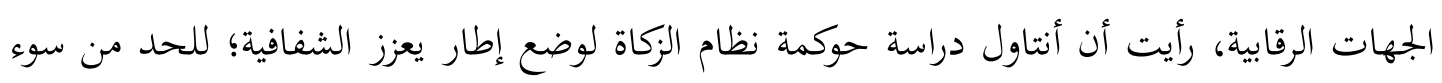
إدارة الزكاة وما يلحقه من تبعات وعواقب تدمر الأمة اجتماعيا واقتصاديا.

ولا تعرف الحوكمة من منظور شرعي، غير أن دلالتها لا تخرج عن إطار مقاصد الشريعة في



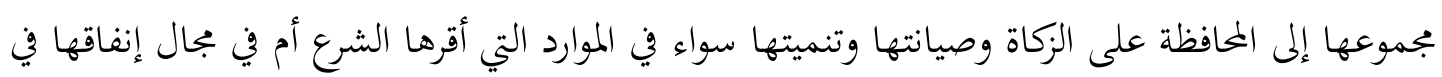

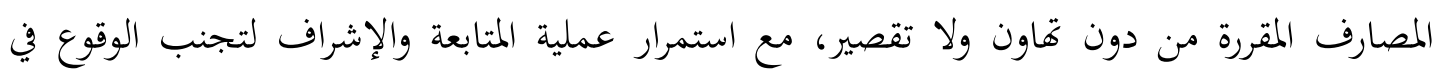

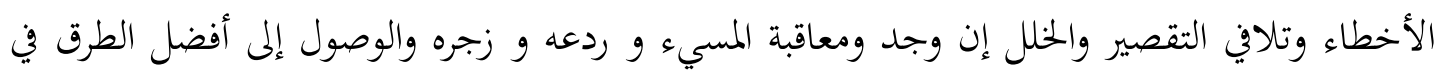
إدارة هذه الأموال بالنظر إلى مصلحة الأمة واستقرارها بعامة (1).

لهذا أصبح البحث عن آليات وطرق جديدة امر ضروري لتفعيل أدائها، ولعل إدراج آليات الحوكمة بمؤسسات الزكاة من شأنه أن يساهم في تحقيق كفاءة الإدارة ويعزز الثقة بين هذه المؤسسات إنسات

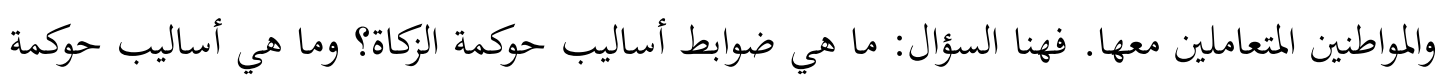
الزكاة في ضوء مقاصد الشريعة؟ فلذلك كان البحث يهدف إلى بيان ضوابط معايير حوكمة الزكاة في ضواء ضواء مقاصد الشريعة وبيان أساليب حوكمة الزكاة في ضوء مقاصد الشريعة.

(1) الإدارة في الإسلام، أحمد إبراهيم أبوسن، مكتبة وهبة- القاهرة، عام 1984م،ط1، ص: 143. 
البصيرة: مجلة الاراسات الإسلامية

AL-BASHIRAH: JOURNAL OF ISLAMIC STUDIES

Vol. 2 No. 2 (2020): 221-237

ISSN: $2807-2170$

Website: https://journal.stiba.ac.id

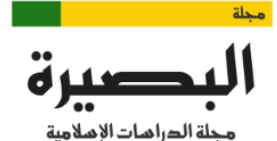

مجلة الصراهات الإصلامية

AL-BASHIRAH

المنهج المستخدم في هذا البحث هو منهج مختلط: المنهج الاستقرائي؛ وذلك يكون بتتع وجمع الأدلة والآراء الفقهية. المنهج الوصفي: وهو دراسة المسألة الفقهية ووصفا وصفا دقيقا، وبيان وجه ارتباطها مع المسائل الأخرى. المنهج التحليلي: وهو منهج يقوم على دراسة الإشكالات في المسألة الفقهية تفكيكا أو تركيبا أو تقويما، ويكون بدراسة طبيعتها ووظائفها و بإرجاع العناصر إلى أصولها. أما الدراسات السابقة المتعلقة بهذا البحث فحسب تتبع الباحثين لتلك المهمة, حصلا على ما

1- حوكمة نظام الزكاة، مصطفى أمين محمد علي، رسالة ماجستير، إشراف، منذر قحف، جامعة حمد بن خليفة- قطر، عام 2017م. تناولت الدراسة ملامح حوكمة الزكاة في العصر النبوي وعصر الخلفاء الراشدين بهدف الخروج منهما بتصور للإطار النظري لحوكمة الزكاة، وقسمها إلى فصل تمهيدي وثلاثة فصول تناول فيهم: ملامح حوكمة الزكاة في العهدين النبوي والراشدي، والبنية السياسة والإدارية لحوكمة نظام الزكاة، ويعد بحثه من أوائل الأبحاث التي تناولت حوكمة الزكاة.2 2 2- المقاصد الشرعية لنظام الزكاة، للباحث رشيد السمغولي بن أحمد, بحث نشر في بجلة جامعة القدس للبحوث الإنسانية، العدد46، عام 2018م. 3

وقد اشتمل هذا الموضوع على عدة فوائد يمكن إجمالها في النقط الآتية: 1. تتبع أهميته من أهمية موضوعه؛ وهو البناء المقاصدي من جهة وحوكمة الزكاة من جهة أخرى.

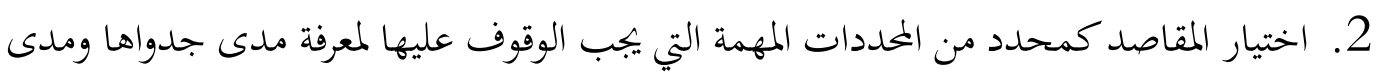
إمكانية تفعيلها و تأثيرها في الأحكام الشريعة. 3. إمكانية توظيف المقاصد والاستفادة منها في قضايا مستجدة.

\section{المبحث الأول: مفهوم الحوكمة ومعاييرها في ضوء مقاصد الشريعة}

$$
\begin{aligned}
& \text { (2) مصطفى أحمد أمين. حوكمة نظام الزكاة. رسالة ماجستير. جامعة حمد بن خليف- قطر. 2017م. } \\
& \text { (3) رشيد السمغولي بن أحمد, "المقاصد الشرعية لنظام الزكاة", مجلة جلمعة القدس المفتوحة للبحوث الإنسانية }
\end{aligned}
$$

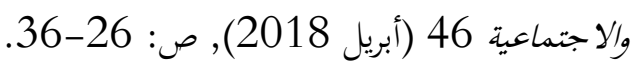


البصيرة: مجلة الاراسات الإسلامية

AL-BASHIRAH: JOURNAL OF ISLAMIC STUDIES

Vol. 2 No. 2 (2020): 221-237

ISSN: $2807-2170$

Website: https://journal.stiba.ac.id

|

مجلة الدراهات الإصلامية

AL-BASHIRAH

المطلب الأول: مفهوم الحوكمة لغة

الحوكمة على وزن فوعلة، ويعتبر لفظ مستحدثا في اللغة العربية، وهو ما يطلق عليه النحت في

اللغة، وهو لفظ مستمدد من الحكومة، والحكومة تعني الانضباط والسيطرة والحكمم، فلفظ الحوكمة يتضمن

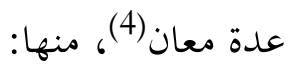

1- الحِكمة: العلم بحقائق الأشياء، ووضع الشيء في موضعه(5) وهي ما تقتضيه من التوجيه والإرشاد. 2- الحوكم: هو العلم والفقه، وقيل هو القضاء بالعدل(6)، والحكم ما تقتضيه من الرجوع إلى مرجعيات أخلاقية وثقافية وإلى خبرات تم الحصول عليها من خلال تحارب سابقة. 3- الاحتكام: طلبا للعدالة خاصة عند انحراف سلطة الإدارة وتلاعبها بمصالح المساهمين.

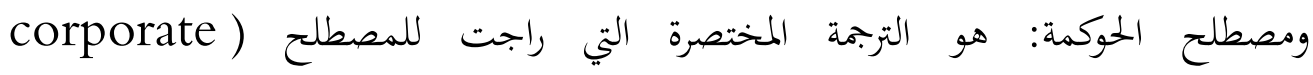
Governance التمويل الدولية (IFC): بأهما النظام الذي تيم من خلاله إدارة الشركات والتحكم في أعماله(7). وعرفت أيضا بأها: هي مجموعة من القوانين والنظم والقرارات التي تحدف إلى تحقيق الجودة والتميز في الأداء عن اختيار الأساليب المناسبة والفعالة؛ لتحقيق خطط وأهداف الشركة أو المؤسسة(8). ومن هذه التعاريف يتبين أن الحوكمة تعنى النظام، أي وجود بجموعة من النظم أو الأطر التي تحكم العلاقت بين الأطراف الأساسية في المؤسسة التي تؤثر في الأداء، كما تشمل المقومات التي تساعد على تقوية المؤسسة على المدى البعيد وتحديد المسؤول والمسؤولية التي تعنى بتنفيذه وتطبيقه في الواقع المعيش. فالحوكمة هي الوسيلة التي تمكن المجتمع من التأكيد من حسن إدارة مؤسسات الدولة والهيئات

(4) دور آليات الحوكمة للحد من الفساد المالي والإداري: بربريس، شريف، جامعة الجزائر، بحث ومقال، ص: 4.

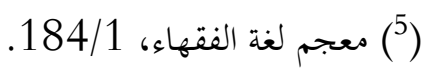

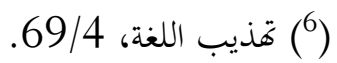

$$
\begin{aligned}
& \text { (77) محددات الحوكمة ومعاييرها، محمد يوسف، بنك الاستثمار القومي- القاهرة، ص: } 4 . \\
& \text { ( المرجع السابق، ص: } 4 .
\end{aligned}
$$




\section{البصيرة: مجلة الاراسات الإسلامية \\ AL-BASHIRAH: JOURNAL OF ISLAMIC STUDIES \\ Vol. 2 No. 2 (2020): 221-237 \\ ISSN: $2807-2170$ \\ Website: https://journal.stiba.ac.id \\ 1) \\ مجلة الصراهات الإهلامية \\ AL-BASHIRAH}

الاقتصادية ومنظمات الأعمال، بطريقة تحمي أموال جميع أفراد ذلك المجتمع، أو هي تدعيم مراقبة نشاط المؤسسة ومتابعة مستوى أداء القائمين عليها(9).

وتعد الحوكمة من المفاهيم التي استحدثت في العلوم الاقتصادية والاجتماعية في أعقاب الاهيارات

الكبرى التي ضربت اقتصاديات بعض الدول(10)، وتزايدت أهميتها نتيجة لابحاه كثير من دول العالم إلى التحول إلى النظم الاقتصادية الرأسمالية، التي يعتمد فيها بدرجة كبيرة على الشركات الخاصة لتحقيق معدلات مرتفعة ومتواصلة من النمو الاقتصادي، وقد أدى اتساع حجم المشروعات إلى انفصال الملكية عن الإدارة، مما أدى إلى ضعف آليات الرقابة على تصرفات المديرين وإلى وقوع كثير من الشركات في أزمات مالية، مما دفع العالم لزيادة الاهتمام بالحوكمة(11).

المطلب الثاني: مفهوم حوكمة نظام الزكاة

حوكمة النظام الزكاة هي:" عملية يتم من خلالها وضع وتنفيذ مجموعة من النظم أو الأطر أو

الهياكل، التي تحدد العلاقات و أساليب اتخاذ القرارات وممارسة السلطات بين الوحدات المعنية بجمع أموال الزكاة والمديرين لما، وغيرهم من المزكين والمستحقين و أصحاب المصلحة، وفقا لقواعد وقوانين ومعايير واضحة ومحددة ومَعنيَّة بالأنشطة الخاصة بالزكاة" (12).

والغاية الرئيسية من حوكمة حساب وصرف الزكاة: هي أن تكون جميع المعلومات المتعلقة بالزكاة

دقيقة وكافية ومتاحة في الوقت المناسب؛ لأجل السماح لمختلف أصحاب المصلحة بالتخاذ القرارات المناسبة من أجل تحقيق الأهداف المحددة. كما أنه لا بد للمؤسسات المالية الإسلامية من ابتاع سياسة الإفصاح والشفافية، بحيث تكون هذه السياسة حاضرة في كل ما يتعلق بحساب وصرف الزكاة، و أن تشتمل سياسة الإفصاح والشفافية على المبادئ الأخلاقية، وأن يتم الإفصاح لأصحاب المصلحة بشكل منتظم، وأن يتم تحري الصدق والعدل في نشر كل ما يتعلق باحتساب وصرف الزكاة. كما أن اتباع المبادئ

$$
\begin{aligned}
& \text { (1) الحوكمة أو الثروة، محمد طارق يوسف، ص: } 4 . \\
& \text { (10) الازمة التي حدثت في دول جنوب شرق آسيا، عام 1997م. }
\end{aligned}
$$

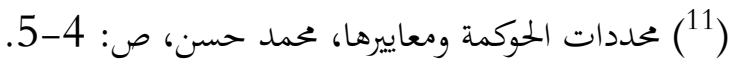

(12) حوكمة نظام الزكاة، مصطفى أحمد أمين، رسالة ماجستير، جامعة حمد بن خليفة- قطر، 2017م، ص: 18. 
البصيرة: مجلة الاراسات الإسلامية

AL-BASHIRAH: JOURNAL OF ISLAMIC STUDIES

Vol. 2 No. 2 (2020): 221-237

ISSN: $2807-2170$

Website: https://journal.stiba.ac.id

البصيرة

مجلة الصراهات الإصلامية

AL-BASHIRAH

السليمة للحوكمة يؤدي إلى توفير الاحتياطات اللازمة ضد الفساد الإداري، ويسهم في تشجيع وترسيخ الشفافية في الحياة الاقتصادية.

المطلب الثالث: معايير حوكمة الزكاة في ضوء مقاصد الشريعة

حرصت العديد من المؤسسات على دراسة مفهوم الحوكمة وتحليله ووضع معايير محددة لتطبيقه، من هذه المؤسسات: منظمة التعاون الاقتصادي والتنمية، وبنك التسويات الدولية BIS ممثلا في لجنة بازل(Basel ${ }^{(13) ~ و م و ٔ س س ة ~ ا ل ت م و ي ل ~ ا ل د و ل ي ة ~ ا ل ت ا ب ع ة ~ ل ل ب ن ك ~ ا ل د و ل ي . ~ و ب ع د ~ ا ل ن ظ ر ~ ف ي ~ ه ذ ه ~ ا ل م ع ا ي ي ر ~ ذ ك ر ~ ا ل ب ا ح ث ا ن ~}$ أهم المعايير التي اتفقوا عليها والتي يمكن توظيفها في حوكمة الزكاة، فالحوكمة تعتمد على مدى قوة تطبيق المؤسسات المختصة بالزكاة مفاهيم الحوكمة القائمة على (14):

$$
\begin{aligned}
& \text { 1) وجود أساس لإطار فعال للحوكمة. } \\
& \text { 2) سيادة القانون على الجميع. } \\
& \text { 3) القدرة على المساءلة لكل المؤسسات الخاصة والعامة في الدولة. } \\
& \text { 4) الشفافية- المشاركة - الآليات. }
\end{aligned}
$$

(13) وقد تبنت لجنة بازل معايير منظمة التعاون الاقتصادي والتنمية للحوكمة، وأصدرت وثيقة في سبتمبر 1999م حول تعزيز الحوكمة في المنظمات المصرفية، وقامت بنشرها لتعزيز أهمية تلك المعايير لضمان أن هناك حوكمة فعالة في كل منظمة مصرفية؛ حتى تستطيع الرقابة المصرفية أن تعمل بكفاءة، وقد تضمنت الوثيقة مجموعة من الممارسات من

1) الحد من الأنشطة والعلاقات التي تقلل كفاءة الحوكمة، ومنها تضارب المصالح والإقراض بشروط ميسرة.

2) إرساء أهداف استراتيجية داخل المنظمة المصرفية وتطبيق مبدأ"TONE at The TOP".

$$
\begin{aligned}
& \text { 3) وضع خطوط للمسؤولية والمساءلة داخل المنظمة المصرفية. } \\
& \text { 4) قيام مجلس الإدارة بإرساء لجان متخصصة. } \\
& \text { 5) توفير بيئة مناسبة للحوكمة من خلال إصدار القوانين والتشريعات والإفصاح. } \\
& \text { (14) الحوكمة أو الثروة، محمد طارق يوسف، ص: } 4 .
\end{aligned}
$$


البصيرة: مجلة الاراسات الإسلامية

AL-BASHIRAH: JOURNAL OF ISLAMIC STUDIES

Vol. 2 No. 2 (2020): 221-237

ISSN: 2807-2170

Website: https://journal.stiba.ac.id

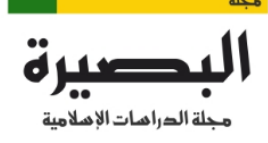

AL-BASHIRAH

5) النظم الضامنة الكفيلة لإقامة هذه المبادئ وفق خصائص كل بلد، وطبيعة النظم الحاكمة

في يالجهات المطبق عليها أصول الحوكمة، وصولا بالمجتمع إلى تحقيق العدالة وتساوي الفرص

$$
\text { والشفافية والمصداقية. }
$$

\section{المطلب الرابع: مرجعية الحوكمة في الشريعة الإسلامية}

لم يضع الإسلام نظاما محددا لشكل الحوكمة ولا لتنظيم سلطاها ولا اختيار أهل الحل والعقد

فيها، وإنما اكتفى بالنص على الدعائم الثابتة التي ينبغي أن تعتمد عليها نظم كل حكومة عادلة ولا تختلف فيها أمة عن أمة؛ كل العدل والشورى والمساواة والأمانة وغيرهان أما عدا هذه الأسس من النظم التفصيلية النهية فقد سكت عنها ليتسع لأولي الأمر أن يضعوا نظمهم ويكونوا بجالسهم ويشكلوا حكومتهم بما يلائم

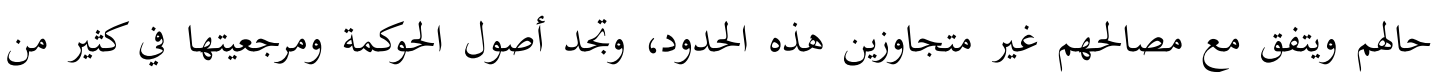
نصوص القرآن والسنة وأفعال الصحابة(15).

1- أصول الحكومة في القرآن الكريم: اشتمل القرآن الكريم على كثير من الآيات التي تخض على القيام

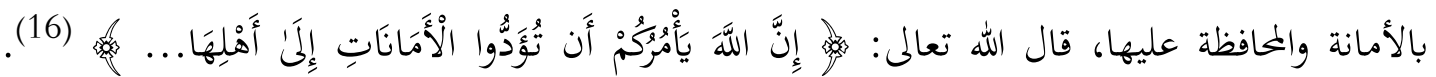
وكذلك ورد في القرآن من الآيات التي تحض على الأمر بالمعروف والنهي عن المنكر كقوله تعالى:

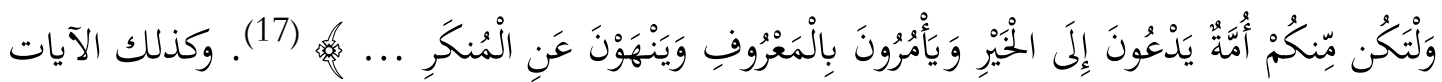

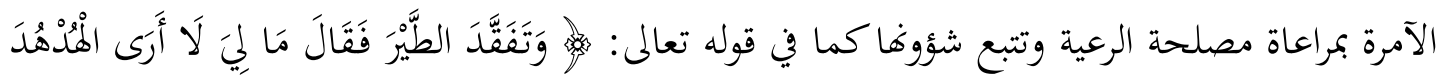

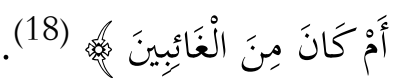

وفي نظام الزكاة ما يدل على ذلك أيضاكتعليق جباية الزكاة بالولاة، فقال الله تعالى:

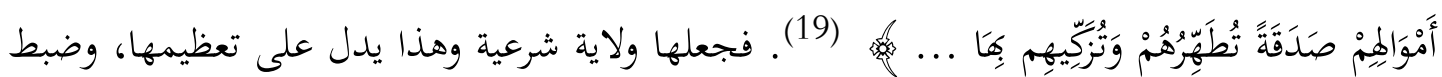

$$
\begin{aligned}
& \text { (15) السياسة الشرعية، عبد الوهاب خلاف، دار الأنصار - القاهرة، 1973م، ص: } 24 . \\
& \text { (17) مورة النساؤ، الآية: } 58 \text { (16) } \\
& \text { (18) سورة آل عمران، الآية: } 104 \text { (17) } \\
& \text { (19) (18) سورة النمل، الآية: } 20 \text { (19) } \\
& \text { (19) - (19) سورة التوبة، الآية: } 103 .
\end{aligned}
$$


تحصيلها، وتحقيق العدل عند جبايتها، وتحمل مسؤوليتها، ولا يتحقق ضبطها والعدل فيها إلا بأمانة

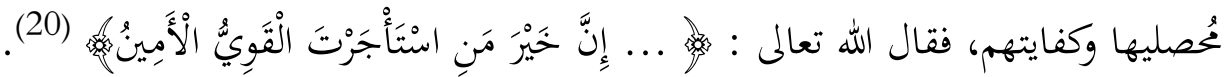
2- أصول الحوكمة في السنة النبوية: ظهر في السنة مدى التزام الرسول صلى الله عليه وسلم الامتثال بالتشريع القرآي في إدارة أموال الزكاة، بقوله للرجل الذي سأله أن يعطيه من مال الزكاة فقال: \ا إن الله لم يرض بحكم نبي ولا غيره في الصدقات، حتى حكم هو فيها، فجزأها ثمانية أجزاء، فإن كنت من تلك الأجزاء أعطيتك 《) (21) فبين له النبي أن الأمر ليس بيديه، فتبين من هذا النص أن هناك التزاما نبوياً بالنص الشرعي.

كما أوجبت السنة النبوية في كثير من ترتيبها الحكم والإدارة على ولي الامر، كقيامه بالأنشطة الإدارية والمالية متفقة مع القواعد التي وضعها الشرع؛ لتضمن نزاهة الحكم وعدالته وشفافيته، والأحاديث في ذلك أكثر من أن تحصى كقول النبي - صلى الله عليه وسلم - : لا إذاكان أمراؤكم و أغنياؤكم سمحاءكم وأمركم شورى بينكم فظهر الأرض خير لكم من بطنها، وإذاكان أمراؤكم شراركم وأغنياؤكم

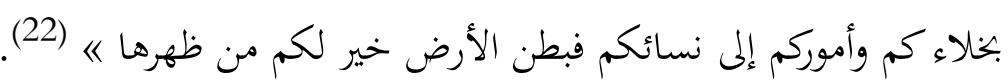
وفي فريضة الزكاة ما يدل على ذلك أيضا، فقد ورد في السنة أن النبي صلى الله عليه وسلم وخلفاؤه من بعده بعثوا السعادة ليجبوا الزكاة من أصحاب الأموال، وقد نقل ابن المنذر الإجماع على ذلك ورنك وقال:" وأجمعوا على أن الزكاة كانت تدفع لرسول الله ولرسله وعماله وإلى من أمر بدفعها إليه"(23).

قال ابن تيمية: " فاما استخراجها و حفظها فلا بد فيه من قوة و أمانة فيولى عليها شاد قوى

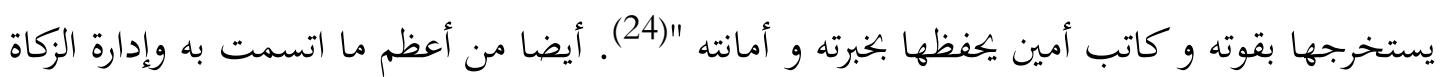
في العهد النبوي وثائق الزكاة التي كات على عهد النبي صلى الله عليه وسلم، فقد كان النبي يبعث بالكتب

$$
\text { (20) سورة القصص، الآية: } 26 .
$$

(1) أخرجه الترمذي في سننه، كتاب الزكاة، باب بَابُ مَنْ يُعْطِي مِنَ الصَّدَقَة، وَحَدُّ الْغنِىى، حديث رقم: 1630.

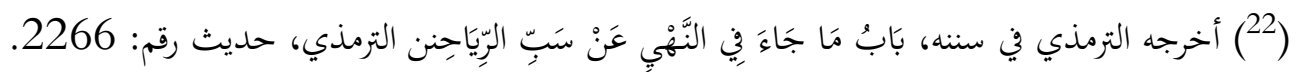
(23) الإجماع لابن المنذر، ص: 48. 258/28. 
البصيرة: مجلة الاراسات الإسلامية

AL-BASHIRAH: JOURNAL OF ISLAMIC STUDIES

Vol. 2 No. 2 (2020): 221-237

ISSN: $2807-2170$

Website: https://journal.stiba.ac.id

البحصيرة

مجلة الصراهات الإصلامية

AL-BASHIRAH

إلى عماله وفيها قرائض الصدقة وشروطها؛ حتى لا بتحد الحقوق أو تضيع، وكانت هذه الوثائق تعد مرجعا لمن بعده من المسؤولين عن الزكاة وأهل العلم"(25).

كما اشتمل القرآن والسنة الراشدة على كثير من القواعد والأحكام الدالة على أن الأداء الوظيفي

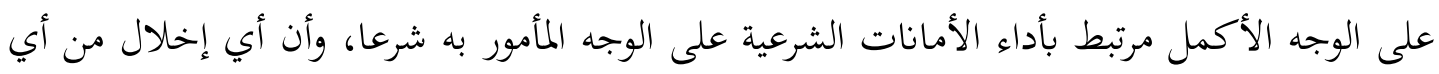

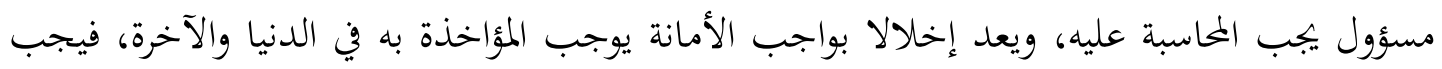

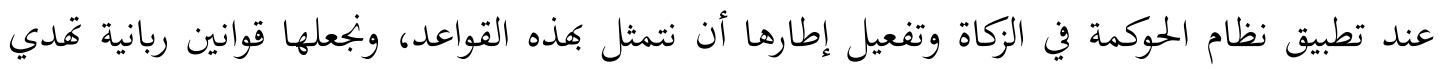
الأمم إلى ما فيه الخير والصلاح.

3- أصول الحوكمة في افعال الصحابة: امتلأت الكتب بكثير من الشواهد الدالة على التربية الإيمانية في

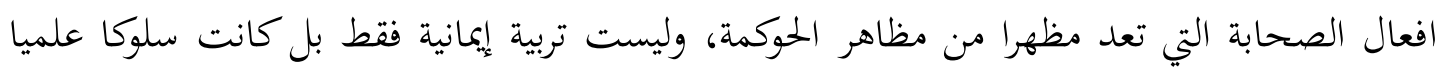



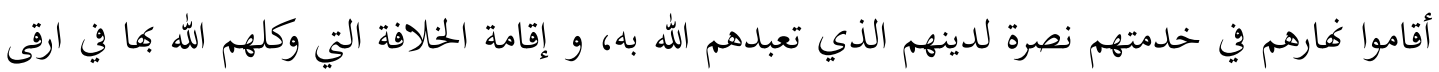
صورها فجعلوا منظومة الحكم الراشد جزءاً من هذه العبادة(26).

فأبوبكر الصديق عند توليه مسؤولية الخلافة خطب في الناس فقال: " أيها الناس فإني قد وليت

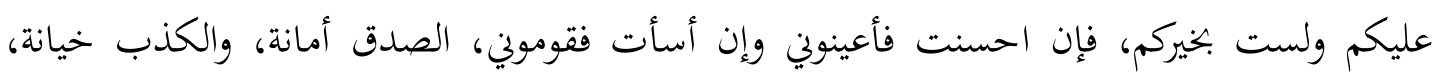

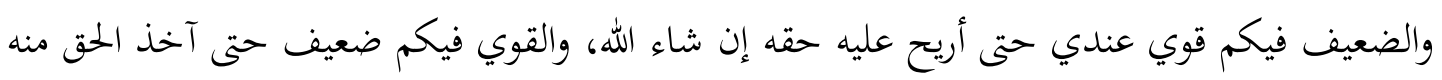

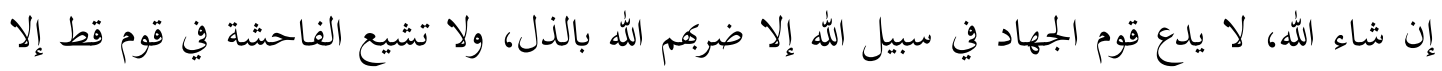

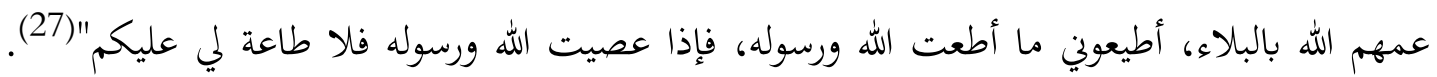

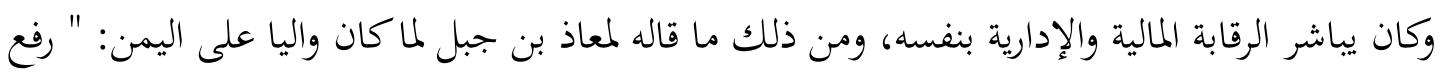

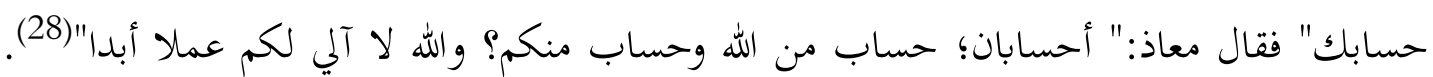

(25) المعايير الإسلامية للحوكمة الرشيدة، ليلى أحمد سالم المشرحي، مجلة التجديد، م 22، العدد 43، 2018م.

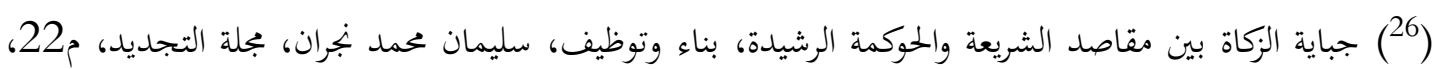
2018، 2018. 43 (27) تاريخ الأمم والملوك: عبد السلام التنوجي، جمعية الدعوة الإسلامية العالمية، طرابس، 1994م، ص: 7. (28) عيون الأخبار، عبد الله بن مسلم ابن قتيبة، بيروت، دار الكتب العلمية، 25/1. 
كما أرسى أبوبكر في خلافته أسلوب الردع وإنفاذ أوامر الشرع في الزكاة ومحاربة مانعي الزكاة؛ ليقتدي به من بعده في أنه لابد من وجود قوة تحمي الحق وتردع الباطل على مستند راسخ من القرآن والسنة. وورد عن عمر - رضي الله عنه - مثله، فخطب ذات مرة قائلا: " إني لم أبعث عمالي ليضربوا

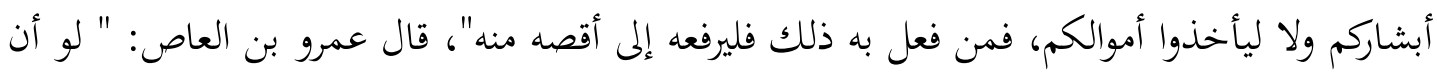

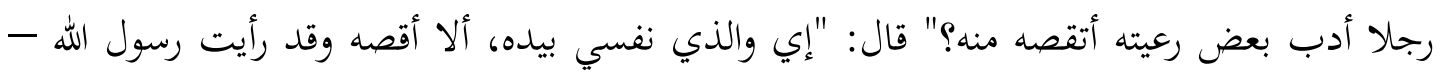
صلى الله عليه وسلم- أقص من نفسه" (29).

ومن ذلك أيضا أن رجلا من عمال عمر - رضي الله عنه - أهدى نمرقتين إلى امرأة عمر فرآهما

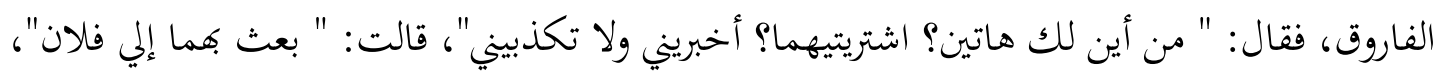

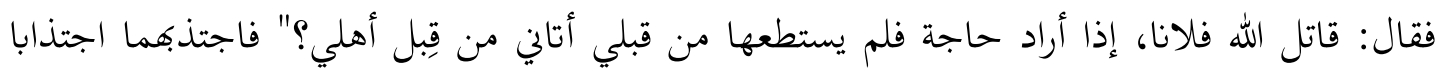

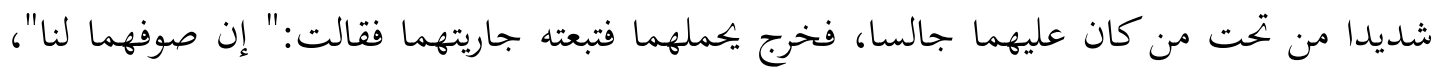

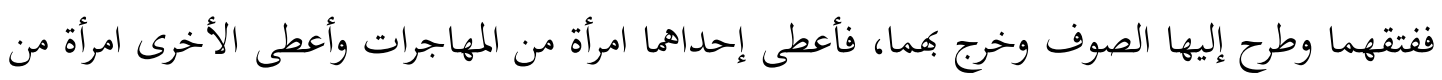

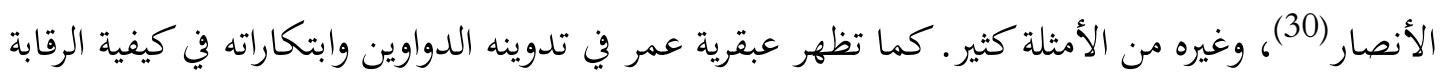



المبحث الثاني: توظيف أساليب الحوكمة وضوابطها في تحقيق مقاصد الثرعية المطلب الأول: كيفية توظيف أساليب الحوكمة في تحقيق مقاصد الزكاة الشرعية

لكي تحقق دور الزكاة الاجتماعي والاقتصادي في المجتمعات الإسلامية، فإنه يتطلب وجود نظام

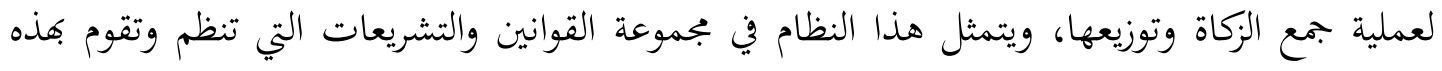

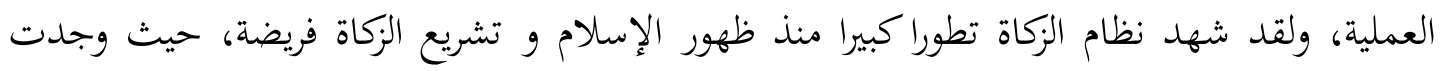

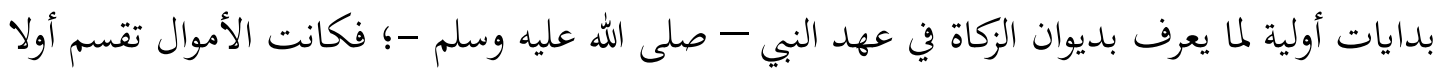

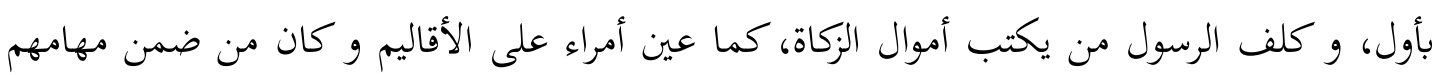
جمع الزكاة، و كان يحاسب العمال بنفسه.

(29) أخرجه أبوداود في سنه، كتاب الديات، باب القود من الضربة، وقصِّ الأمير من نفسه، حديث رقم: 4539.

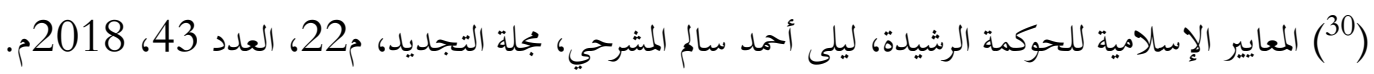


البصيرة: مجلة الاراسات الإسلامية

AL-BASHIRAH: JOURNAL OF ISLAMIC STUDIES

Vol. 2 No. 2 (2020): 221-237

ISSN: $2807-2170$

Website: https://journal.stiba.ac.id

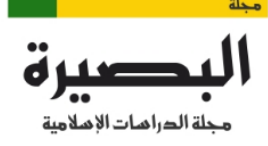

AL-BASHIRAH

وهكذا كان الحال في عهد أبي بكر، و الذي ظهرت في عهده نواة بيت المال مع توسع الدولة

الإسلامية و زيادة مواردها، و في عهد عمر بن الخطاب تطورت الزكاة تطورا ملحوظا مما استوجب وجود نظام لحصرالإيرادات و ضبط المصروفات، فتم استخدام أساليب إدارية جديدة كالفصل بين السلطة القضائية و التنفيذية، و إنشاء ديوان العطاء و الجند(31) و غيرها(32)، و استمرت عملية جمع و توزيع الزكاة عبر الزمان مع وجود اختلاف في درجة التطبيق العملي لها، ثم ضعف تطبيقها في العصور المتأخرة حتى كادت تصبح في بعض البلدان الإسلامية الفريضة الغائبة.

المطلب الثاني: ضوابط أساليب الحوكمة لتحقيق مقاصد الزكاة

1- انضباط أعضاء الجهاز الإداري القائم على تحصيل و توزيع الزكاة: بحيث يكون كل القائمين على إدارة مؤسسات الزكاة متبعين السلوك الأخلاقي و المناسب في كافة أعمالهم، و أن يكونوا على علم كبير بمستحقي الزكاة، و عليهم التأكد من استحقاقهم و تحديد مقدار كفايتهم و ترتيبهم حسب حاجة كل

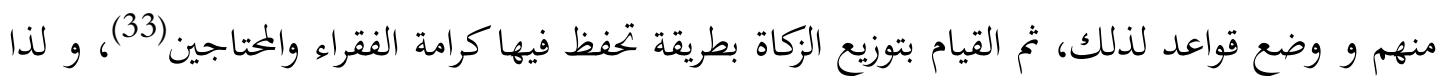
شرط العلماء في العامل على الزكاة: الإسلام، البلوغ، العقل، الأمانة و الكفاية للعمل (34). 2- سيادة أحكام الشريعة على أطراف الزكاة (السعادة وأرباب الأموال وأهلها): فلا يأخذ السعادة أكثر مما وجب على أرباب الأموال، ولا يمنع رب المال ما وجب عليه، ولا تمتد يد أحد من غير أصنافها عليها إليها، فقد قال النبي صلى الله عليه وسلم: " فمن سألها من المسلمين على وجهها فليعطها ومن سأل فوقها لا يعطها"(35). (20)

( ) هو ديوان أنشأه عمر بن الخطاب - رضي الله عنه - ، وكان السبب وراء إنشائه هو إحصاء المقاتلين وتثبيت أسمائهم والعطاء لهم، وتحديد رواتبهم ومواعيدها. (32) دراسة مقارنة لنظم الزكاة الجوانب العامة والإدارية والتنظيمية، فؤاد عبد الله العمر، ص: 21. (33) إدراج أليات الحوكمة ضمن استراتيجية تفعيل أداء مؤسسات الزكاة، عبد الله بن منصور، مجلة الحكمة للدراسات الاقتصادية، ع12ن 2018م، ص: 25. (593/1 فقه الزكاة، يوسف القرضاوي (35) الجامع الصحيح ، البخاري، حديث رقم: 1454. 
البصيرة: مجلة الاراسات الإسلامية

AL-BASHIRAH: JOURNAL OF ISLAMIC STUDIES

Vol. 2 No. 2 (2020): 221-237

ISSN: $2807-2170$

Website: https://journal.stiba.ac.id

|

مجلة الصراهات الإصلامية

AL-BASHIRAH

ومن ضمن سيادة أحكام الشريعة على أطراف الزكاة، وجوب فهم أحكام الزكاة و قوانينها من قبل العاملين عليها، فقانون الشريعة في الزكاة ثابت و واضح لا يتغير، كما يجب على من يوليهم إعطاؤهم

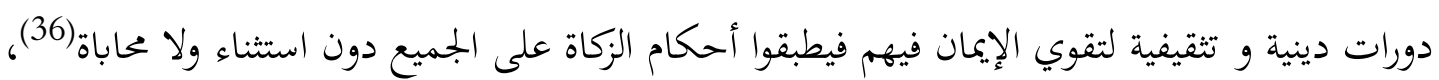
فقد حرض النبي صلى الله عليه وسلم على غرس رقابة الله في نفوس كافة الأطراف المعنيين بالزكاة، بدءاً بعماله و المتصدقين و المزكين، فقال صلى الله عليه وسلم: " العامل على الصدقة بالحق كالغازي في سبيل الله"(37).

1- الشفافية: مفهوم الشفافية في الأصل يعني وضوح التشريعات وسهولة فهمها واستقرارها وانسجامها

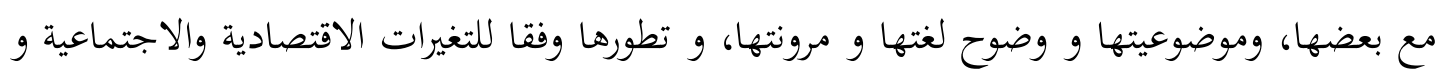
الإدارية و بما يتناسب مع العصر، و تبسيط الإجراءات و نشر المعلومات و الإفصاح عنها و سهولة الوصول إليها بحيث تكون متاحة للجميع، و هي من منظور الشرع تعدل الوضوح و الصفاء و النقاء(38). وتحقق الشفافية في الزكاة يكون في إطار منظومة متكاملة من القيم الشرعية، أهمها أن صلاح الأمة في صلاح الأئمة أو من ينوب عنهم ممن يتولى أمر الزكاة، و وجوب استكفاء الأمناء وتقليد النصحاء فيما يفوض إليهم من الأعمال و يوكل إليهم من أموال، ففي الزكاة أكد الرسول الله صلى الله عليه وسلم على ئى

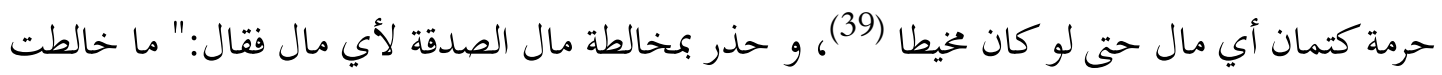
الصدقة مالا إلا أهلكته"(40)، و لذا وضع عمر بن الخطاب السجلات والدواوين لتكتب مصارف الزكاة وتضبط الأمول المأخوذه من أصحابها في قدرها وصفتها والإفصاح عنها دوريا، وتدوين هذا في وثائق رسمية و كيفية صرف هذه الأموال و أسماء الذين يأخذوها، قال النووي:" وينبغي للإمام و الساعي إذا

(26) جباية الزكاة بين مقاصد الشريعة والحوكمة الرشيدة- بناء وتوظيف، سليمان محمد نجران، مجلة التجديد، م 22،

$$
\begin{aligned}
& \text { ع 2018، 2018م. } \\
& \text { 349/3. }
\end{aligned}
$$

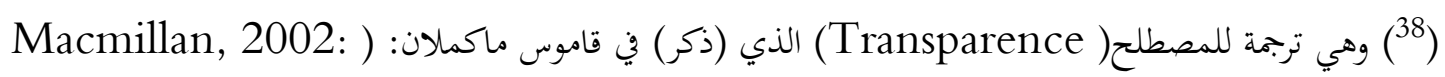
1530, 1531 (1531)، تعريف الشفافية الإدارية: مقال، منى حيدر الطائي، عام 2017م. (1833) (المسند الصحيح: مسلم، حديث رقم (1839). ( (40) السنن الصغرى، البيهقي، حديث رقم (1318). 
البصيرة: مجلة الاراسات الإسلامية

AL-BASHIRAH: JOURNAL OF ISLAMIC STUDIES

Vol. 2 No. 2 (2020): 221-237

ISSN: $2807-2170$

Website: https://journal.stiba.ac.id

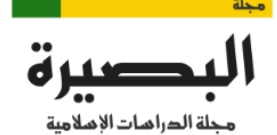

مجلة الصراهات الإصلامية

AL-BASHIRAH

فوض إليه تفريق الزكوات أن يعتني بضبط المستحقينن و معرفة أعداد هم و قدر حاجاهم واستحقاقهم، بحيث يقع الفراغ من جميع الزكوات بعد معرفة ذلك أو معه ليتعجل وصول حقوقهم إليهم"(41). 2- المساءلة: و تعتبر المساءلة من أهم معايير الحوكمة، و التي لا تحقق المقصود منها وفق مقاصد الشريعة إلا في إطار الرقابة المحكمة و العادلة التي لا تستثني ولا تحابي أحد|(42)، كما ثبت عن النبي صلى الله عليه وسلم محاسبة عمال الصدقات، روى البخاري:" أن النبي استعمل رجل من الأزد يقال له ابن اللتبية جعله عاملا على الصدقة وعلم أنه أهدي له هدية فحذره و اشتد تحذيره من هذا"(43)، وقال: " هلا جلس في بيت أبيه فينظر أيهدي له أم لا؟ والذي نفسي بيده لا يأخذ أحد منكم شيئا إلا جاء يوم القيامة يحمله على رقبته" (44) بل و قام البي صلى الله عليه وسلم و خطب في في الناس مستنكرا تلك لك الفعلة، و هذا الحديث فيه ملمح من ملامح المحاسبة و الشفافية، كما أنه نموذج أولي في تطبيق مبادئ الحوكمة، التي ترمي في الأساس إلى منع الفساد و حفظ الحقوق الخاصة بصدقات المسلمين، كما أن من منات عرضه الأمر على جماعة المسلمين في خطبته كان ليعالجه على نطاق أوسع و يستأصل المشكلة من جذورها، و ليرسي نموذج رائدا في المحاسبة و المكاشفة و الشفافية و الإفصاح لأصحاب المصلحة (45). 3- الاستقلالية: واستقلالية أداء أنشطة مؤسسة الزكاة من العناصر المهمة لحوكمة الزكاة، فلا تتعرض المؤسسات إلى أي ضغوط داخلية أو خارجية تجعلها تتحرف عن أداء وظائفها، فيجب ألا تخشى أي دوائر - مهما كانت درجة سلطتها أو نفوذها في المجتمع - حتى تتمكن من بلوغ أهدافها المسطرة ضمن استراتيجياتا(46)؛ لأن الزكاة نظام مؤسَّيٌّ يتمتع بالاستقلالية المالية و الإدارية، و إن كانت خاضعة

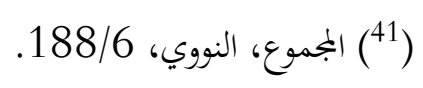

( المعايير الإسلامية للحوكمة الرشيدة، ليلى أحمد سالم المشرحي، ص: 38. (4) (4) البخاري، حديث رقم: 7197. 220/5 البخاري.

(45) حوكمة نظام الزكاة: مصطفى أحمد أمين، رسالة ماجستير، جامعة حمد بن خليف- قطر، ص: 35. (46) أهمية تطبيق مبادئ الحوكمة في التنظيمات المؤسساتية للزكاة، المؤتمر العالمي التاسع للاقتصاد والتمويل الإسلامي بإسطنبول، تركيا، منصور عبد الله، بزاوية عبد الحكيه، ص: 17. 
البصيرة: مجلة الاراسات الإسلامية

AL-BASHIRAH: JOURNAL OF ISLAMIC STUDIES

Vol. 2 No. 2 (2020): 221-237

ISSN: $2807-2170$

Website: https://journal.stiba.ac.id



مجلة الصراهات الإصلامية

AL-BASHIRAH

لإشراف الدولة و رقابتها، و هو ما يستدل عليه من خلال مصرف العاملين عليها و إرسال النبي صلى الله عليه وسلم عُماله إلى المناطق المختلفة لتحصيل الزكاة وصرفها.

4- العدالة في توزيع أموال الزكاة على الفقراء و المحتاجين: وهي أن تقوم مؤسسات الزكاة بتوزيع حصيلة الزكاة على مستحقيها حسب درجة الحاجة، و العدالة المنشودة في الإسلام هي إحقاق الحق على جميع الأصعدة سواء كانت اجتماعية أو اقتصادية أو مالية(47).

5- المسؤولية الاجتماعية لمؤسسة الزكاة: لأن تماسك المجتمعات يتوقف على سيادة المسؤولية الاجتماعية التي تحقق التكافل والتآزر بين جميع أطراف المجتمع، و لا يحدث ذلك إلا إذاكانت مؤسسات الزكاة متجذرة في المجتمع و تستعد قوتا وثقتها من محيطها المجتمعي الذي توجد فيه(48).

الخاتمة

قد توصل الباحثان من خلال هذا البحث عدة النتائج المهمة في مسألة حوكمة الزكاة وارتباطها بمقاصد الشريعة, ومما يلي ذكر تلك النتائج: 1- إن الشريعة الإسلامية وضعت لمصالح العباد في الدارين، وإها خالية من العبث بعيدة عن التحكم، قائمة على التعليل وربط الأحكام بأسباب وأوصاف تدور كلها حول مصالح الخلق عاجلا أو آجلا. 2- إن لكل شريعة مبادئها الكبرى ومقاصدها العليا التي أرادت تحقيقها من خلال انتهاج شرعها، وكانت هذه المقاصد في الموجه للأحكام ككل، والأحكام الجزئية سب موصلة إلى تحقيق هذه الكليات. 3- إن للفقه الإسلامي بناء مقصديا هو سرّ نموه وتطوره وإعجازه، وبقدر استيعاب الفقهاء لآليات ومناهج الاستنباط بقدر ما ينمو ويتطور الفقه الإسلامي. 4- معرفة المقاصد وأثرها، وبيان دورها في القضايا المعاصرة للزكاة منها: حوكمة الزكاة.

(المرجع السابق، ص: 17 (47) (48) إدراج آليات الحوكمة ضمن استراتيجية تفعيل أداء مؤسسات الزكاة، عبد الله بن منصور، مجلة المحكمة للدراسات الاقتصادية، ع 12، 2018م، ص: 25. 


\section{البصيرة: مجلة الدراسات الإسلامية}

AL-BASHIRAH: JOURNAL OF ISLAMIC STUDIES

Vol. 2 No. 2 (2020): 221-237

ISSN: $2807-2170$

Website: https://journal.stiba.ac.id
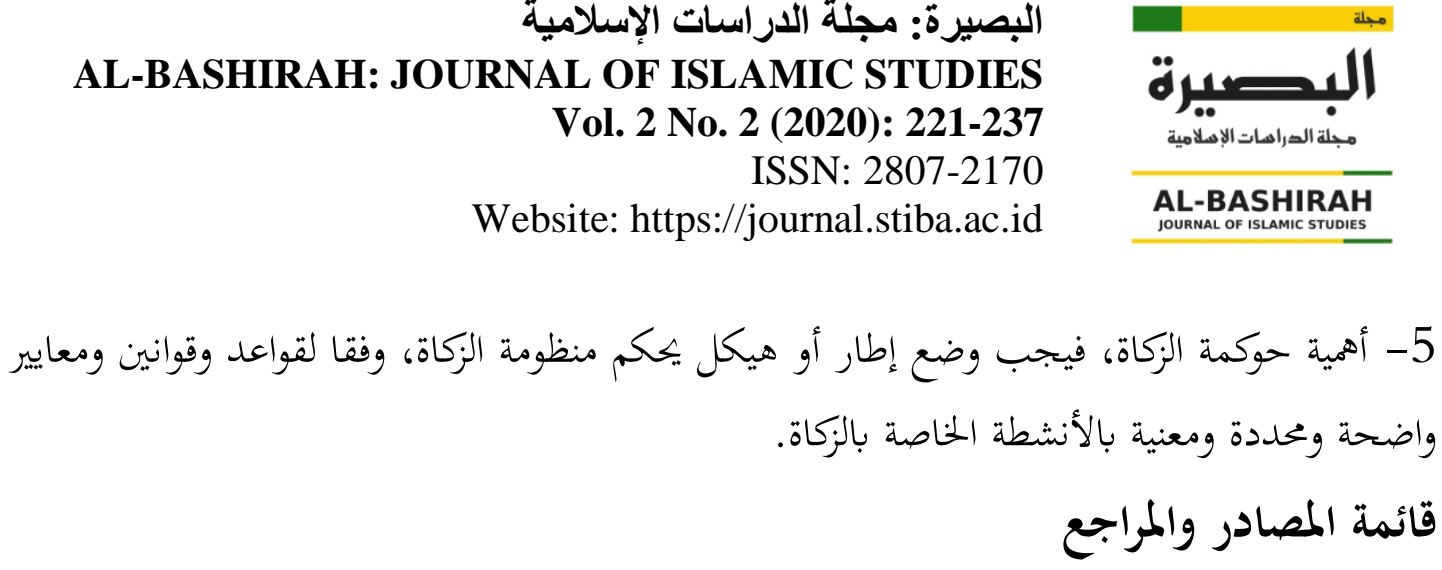

`Abd al-Salām al-Tanūjī. Tārīkh al-Umam wa al-Mulūk. Jam `iyyah al-Da`wah alIslāmiyyah al-`Ālamiyyah. Trabuls, 1994.

`Abd al-Wahhāb Khallāf. Al-Siyāsah al-Syar ìyyah fì al-Syu'ūn al-Dusturiyyah wa alKhārijiyyah wa al-Māliyyah. Al-Ṭab ah: I. Dār al-Qalam, 1988.

'Abdullāh bin Manșūr. Idrāj Āliyāt al-Ḥaukamah Ḍimn Istrātījiyyah Taf'̄̄l Adā' Mu'assasāt al-Zakāh. Majallah al-Hikmah II al-Dirāsāt al-Iqtiṣādiyyah 12, (2018).

Abū Dāwūd, Sulaimān bin al-Asy`aś al-Sijistān̄i. Taḥqīq: Muḥammad Muhỵ̄̄ al-Dīn ‘Abd al-Hamīd. Sunan Abī Dāwūd. Bīrūt: Al-Maktabah al-`Așriyyah Șaidā, dūna sanah.

Abū Muhammad 'Abdullāh bin Muslim bin Qutaibah al-Dīnūrī. 'Uyūn al-Akhbār. Bīrūt: Dār al-Kutub al-'Ilmiyyah, 1997.

Aḥmad Ibrāhīm Abūsun. Al-Idārah fì al-Islām. Al-Ṭab ah: I. Al-Qāhirah: Maktabah Wahbah, 1984.

Al-Baihaqī, Abū Bakr Aḥmad bin Al-Ḥusain bin `Alī. Taḥqīq: `Abd al-Mu`ṭi Amīn Qal`ajī. Al-Sunan al-Ṣugrā. Al-Ṭab ah: I. Bākistān: Dār al-Nasyr, Jāmi`ah alDirāsāt al-Islāmiyyah Kratsȳ̄, 1989.

Al-Bukhārī, Abū `Abdillāh Muḥammad bin Ismā'̄̄l bin Ibrāhīm bin al-Mugīrah alJu fī. Taḥīq: Muḥammad Zuhair bin Nașir al-Nāṣir. Șaḥ̄h al-Bukhārī. AlṬab`ah: I. Bīrūt: Dār Ṭauq al-Najāh, 2001.

Al-Nawawī, Abū Zakariyya Muḥȳ̄ al-Dīn Yaḥyā bin Syaraf. Al-Majmū’ Syarh alMuhażżab. Dār al-Fikr, dūna sanah.

Al-Qarḍ̄̄wī, Yūsuf. Fiqh al-Zakāh: Dirāsah Muqāranah lī Ahkāmihā wa Falsafatihā fì Dau' al-Qur'ān wa al-Sunnah. Al-Ṭab`ah: XXV. Al-Qāhirah: Maktabah Wahbah, 2013.

Al-Tirmiżī, Muḥammad bin 'Īsā bin Saurah bin Mūsā bin al-Ḍaḥḥ̄k. Taḥqīq: Aḥmad Syākir. Sunan al-Tirmżì. Al-Ṭab`ah: II. Bī̄rūt: Dār al-Kutub al-'Ilmiyyah, 1975.

Barbarīs Syarīf. Daur Āliyāt al-Haukamah lī al-Hadd min al-Fasād al-Mālì wa alIdārī. Baḥs wa Maqāl, Jāmi ah al-Jazā'ir.

Fu'ād 'Abdullāh al-'Umar. Dirāsah Muqāranah lī Naẓm al-Zakāh al-Jawānib al‘̄mmah wa al-Idāriyyah wa al-Tanzīmiyyah. Bīrūt: Dār al-Kutub al'Ilmiyyah, 2016.

Ibn Taimiyyah, Taqī al-Dīn Abū al-`Abbās Aḥmad bin `Abd al-Halīm. Taḥqīq: `Abd al-Raḥmān bin Muḥammad bin Qāsim wa Ibnuh Muḥammad. Majmū `Fatāwā Syaikh al-Islām Aḥmad bin Taimiyyah. Dūna țab`ah. Al-Madīnah alMunawwarah: Majma`al-Malik Fahd lī Țibā’ah al-Muṣhaf al-Syarīf, 1995.

Lailā Aḥmad Sālim al-Masyrah̄̄. Al-ma'āyīr al-Islāmiyyah lī al-Ḥaukamah alRasyīdah. Majallah al-Tajdìd 43, al-Raqm 22 (2018). 


\section{البصيرة: مجلة الدراسات الإسلامية \\ AL-BASHIRAH: JOURNAL OF ISLAMIC STUDIES \\ Vol. 2 No. 2 (2020): 221-237 \\ ISSN: $2807-2170$ \\ Website: https://journal.stiba.ac.id

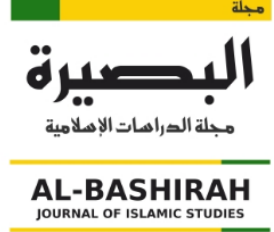

Majma` al-Fiqh al-Islāmī. Dirāsāt fì al-Muhāasabāt al-Zakawiyyah. Min Munāqasyāt al-Syaikh Taqī al-`Aśañ̄.

Manșūr 'Abdullāh. Ahammiyah Tațbīq Mabādi' al-Haukamah fì al-Tanzīmāt alMu'assasiyyah lī al-Zakāh. Al-Mu'tamar al- 'Ālamī al-Tāsi lī al-Iqtișad wa alTamwīl al-Islāmī bī Isțanbūl Turkiya, 2018.

Muḥammad bin Aḥmad bin al-Azharī al-Hurawī Abū Manșūr. Taḥqīq: Muhammad 'Iwaḍ Mur’ib. Tahż̄̄b al-Lugah. Al-Ṭab`ah: I. I. Bīrūt: Dār Iḥyā’ al-Turāì al'Arabī, 2001.

Muhammad bin Ibrāhīm bin al-Munżir al-Naisābūrī. Taḥqīq: Fu’ād `Abd al-Mun `im Aḥmad. Al-Ijmā’ 'Al-Ṭab ah: I. Dār al-Muslim lī al-Nasyr wa al-Tauzī', 2004.

Muhammad Rawās Qal `ajī. Mu jam Lugah al-Fuqahā'. Al-Ṭab`ah: II. Dār al-Nafā’ is lī al-Ṭibā’ah wa al-Nasyr, 1988.

Muhammad Ṭāriq Yūsuf. Al-Haukamah au al-Śarwah. Al-Ṭab`ah: II. Maktab Jrānat Sūruntūn Muhammad Hilāl, 2012.

Muhammad Yūsuf. Muḥaddāt al-Haukamah wa Ma āỳìruhāa. Al-Qāhirah: Bank alIstis̀mār al-Qaumī, 2007.

Muslim, Abū al-Hasan Muslim bin al-Hajjāj bin Muslim al-Qusyairī al-Naisābūrī. Taḥqīq: Muḥammad Fu'ād 'Abd al-Bāqī. Sahạ̄h Muslim. Bīrūt: Dār Iḥyā' alTurās̀ al-`Arabī, duna sanah.

Muștafā Aḥmad Amīn. Haukamah Niẓām al-Zakāh. Risālah Mājistīr. Jāmi`ah Ḥamad bin Khalīfah bī Qațar, 2017.

Sulaimān Muḥammad Najrān. Jibāyah al-Zakāh baina Maqāṣid al-Sarī’ah wa alHaukamah al-Rasyīdah, Binā' wa Tazīf. Majallah al-Tajdìd 43, al-Raqm 22 (2018). 